\title{
OPTIMIZE THE PARAMETERS OF DUAL TURNING PROCESS USING TAGUCHI METHODOLOGY
}

\begin{tabular}{c} 
Ravindra Nath Yadav \\
Department of Mechanical Engineering, \\
BBD National Institute of Technology and Management \\
Lucknow-226028, India \\
Email: rnymnnit@yahoo.com \\
\hline
\end{tabular}

\begin{abstract}
Dual turning is a novel metal cutting process to get the desired shape of the rotating workpiece. In this process, two single point cutting tools are penetrated toward workpiece from opposite directions to remove the extra material by cutting action. It is highly complex process due to application of the two cutting tools at a time as which the selection of the optimum parameters is much difficult. The aim of this paper is to optimize the process parameters (cutting speed, feed rate, primary depthof-cut and secondary depth-of-cut) to minimize the surface roughness using Taguchi methodology. For this, the experiments were performed according to the $L_{9}$ design matrix on the dual turning setup at lathe machine. The result shows that optimal condition of the process parameters gives better surface finish as compared to the initial setting of the control parameters.
\end{abstract}

Keywords:- turning, machining, cutting, taguchi, roughness optimization, experimentation

\section{INTRODUCTION}

Manufacturing industries are always facing a lot of difficulties like holding and clamping, chattering/vibration and dynamic instabilities etc. during machining of the rotating parts. Even though, it is the one of the most popular and industrialized process for machining of the circular rotating parts among various existing traditional machining processes $[1,2]$. The basic purposes of turning process are to remove the extra/unwanted material from the external as well as internal surfaces of the rotating workpiece to get the specified dimensions and surface quality [3]. The surface qualities of turned parts mostly depend upon various process parameters. These parameters are controllable (cutting velocity, feed rate, depth-of-cut, cutting fluid, tool material and tool signature etc.) or uncontrollable (temperature, humidity, material composition, machine efficiency etc.). Among various controlled parameters, some process parameters like cutting velocity, feed rate, depth-of-cut, work material, tool material and tool signature are highly affected the performances of the turning process $[4,5]$.

Turning is used for machining of the conventional as well as advanced and difficult-to-machine engineering materials. Due the potential in cutting technology, it is accepted by small as well as large scale industries. The wide applicability of the turning process makes it one of the better choices for the manufacturing industries to cut the material from both the surfaces i.e. external as well as internal. Even though, it suffers with several demerits like finish cut turning after rough cut or multi-pass turning, in which several rough cut follows by finish cut turning [6]. Generally, multi-pass turning is good approach to achieve the desired surface quality but it leads in the overall production cost. To overcome the above problems, a novel cutting process has been introduced and the developed process is named as Dual Turning process.
Dual turning process is an innovative cutting process in which two-numbers of single point cutting tools penetrate toward the workpiece from the opposite sides to cut the extra material from the rotating workpiece as shown in the Fig.1. In this process, both cutting tools are applied simultaneously on a single rotating surface. The basic purpose of the secondary cutting tool is to perform as a finish cut turn operation during turning of workpiece while the primary cutting tool performs as rough cut turning. The mechanism of the metal removal of the dual turning is almost same as normal turning process i.e. plastic deformation, shearing and tearing. The basic purposes of the dual turning process are to eliminate the secondary finish cut operation, minimize the number of passes and increases in the overall productivity.

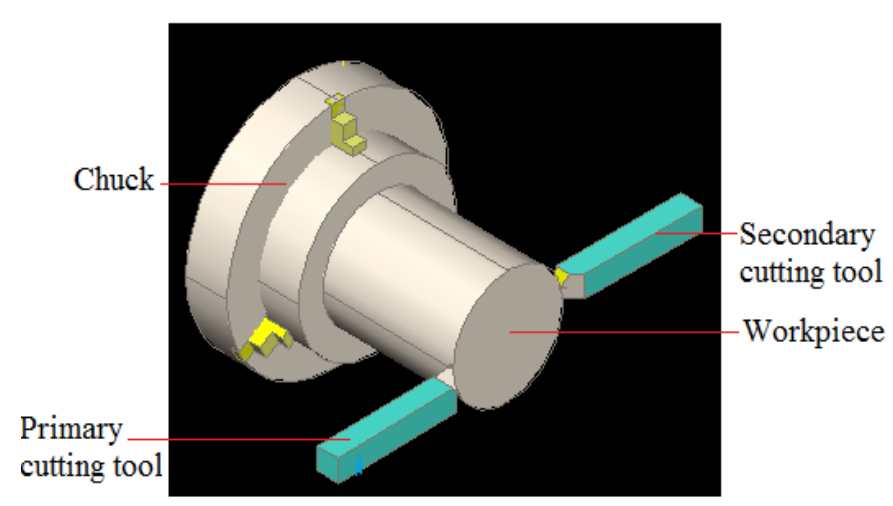

Fig. 1. Dual turning process

The simultaneous application of the two-cutting tool in turning is new approach and a little bit published works are available on it with the name of parallel turning process. Budak et al. [7] analyzed the stability of cutting tools in the parallel turning process. They claimed that the vibration in primary cutting tool is much higher than secondary cutting tool for the same cutting conditions. They also claimed that the tools vibration depends upon cutting speed and increases in cutting speed leads to decrease in the vibration of cutting tools. Kalidasan et al. [8] studied the effects of cutting speed of tool on the tool vibration for multi-tool turning process. Brecher et al. [9] discussed the simulation results for the dynamic stability in the turning process with application of two-cutting tools. They claimed that material removal has been significantly enhanced (approximately 250\%).

Dual turning process becomes highly complex due to the application of the two-cutting tools time on a single rotating workpiece during turning. Therefore, the selection of the optimal process parameters is a difficult task and optimization becomes necessary. In various optimization techniques, Taguchi methodology has been gaining more attention to optimize the process parameters. Generally, Taguchi approach 


\section{Asia Pacific Journals}

needs design matrix to perform the experiments and optimize the process parameters based on the signals to noise $(\mathrm{S} / \mathrm{N})$ ratio for measure the performance characteristics [10].

The applications of Taguchi approach for optimization of the control parameters related to the different machining processes were tested by many researchers [11-13]. Yang et al. [14] optimized the cutting parameters related to the turning operation using Taguchi approach. Nalbant et al. [15] applied Taguchi technique to optimize the control parameters such as nose radius, feed rate and depth-of-cut to minimize the surface roughness of the turned parts. The optimum level of cutting parameters for minimum value of the cutting force and surface roughness were determined using Taguchi method during turning of cast iron by Yucel [16]. Asiturk and Akkus [17] used $\mathrm{L}_{9}$ orthogonal array to optimize surface roughness during hard turning of the AISI 4140 steel. Thamizhmani et al. [18] were also optimized the parameters related to the turning operation using Taguchi approach. Therefore, the Taguchi based optimization technique has been applied to optimize the process parameters of the dual turning process.

The aim of the present study is to optimize the control parameters of the dual turning process. For this purpose, the experiments were performed on the self developed setup on the lathe machine. All the experiments were performed according to the $\mathrm{L}_{9}$ design matrix considering the effect of cutting speed, feed rate, primary depth-of-cut and secondary depth-of-cut on the average surface roughness $(\mathrm{Ra})$. The analysis of variance (ANOVA) technique has been used to analyze the experimental data and also discuss the most influential turning parameters.

\section{EXPERIMANTATION}

All the experiments were performed on the center lathe machine, which was fitted with self developed setup for the secondary-tool post. The secondary-tool post is an additional tool holding attachment, which is mounted at the cross slide of the lathe machine and opposite side of the primary-tool post. The primary tool post is already inbuilt with the lathe machine to hold the primary-tool post. The photographic view of actual experimental setup on the lathe machine has been shown in the Fig. 2. The developed setup has been consisted with lead screw (spindle), tool post and lever. The spindle used to control the secondary depth-of-cut with the help of hand operated lever. The secondary-tool post is used to hold the secondary-cutting tool during turning operations. Generally, both the cutting tools (primary and secondary) are operated with equal feed rate at same cutting speed and unequal depthof-cut during turning the rotating surfaces.

The alloy steel such as AISI 1040 steel $(C=0.435, \mathrm{Si}=0.20$, $\mathrm{Mn}=0.69, \mathrm{P}=0.035, \mathrm{~S}=0.45)$ of diameter $=20 \mathrm{~mm}$ has been chosen as a workpiece material due to wide applicability in the field of dies and mold industries. The cutting tools used for turning was made of high speed steel (HSS). The controlled parameters such as cutting speed, feed rate, primary depth-ofcut and secondary depth-of-cut are taken as input parameters while average surface roughness $\left(R_{a}\right)$ has been taken as performance parameter. The ranges of input parameters were selected after pilot experimentation. The secondary depth-of- cut considered as finish cut operation. Therefore, it is taken as half value of the primary depth-of-cut. The value and level of the each input parameter are summarized in the Table 1. The Mitutoyo (model: SJ-201), surface measuring instrument has been used to measure the Ra value of the turned surfaces.

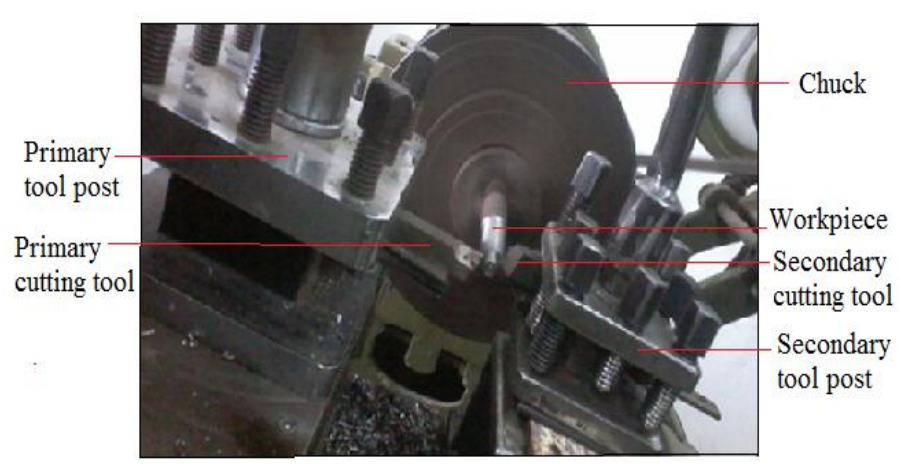

Fig. 2. Experimental setup of dual turning

TABLE 1: Input parameters and their value

\begin{tabular}{lcccc}
\hline Parameter & Symbol & level 1 & level 2 & level 3 \\
\hline $\begin{array}{l}\text { Cutting speed } \\
(\mathrm{m} / \mathrm{min})\end{array}$ & $\mathrm{V}$ & 10 & 20 & 30 \\
$\begin{array}{l}\text { Feed rate }(\mathrm{mm} / \mathrm{rev}) \\
\begin{array}{l}\text { Primary } \\
\text { depth-of-cut }(\mathrm{mm})\end{array}\end{array}$ & $\mathrm{F}$ & 0.20 & 0.40 & 0.60 \\
$\begin{array}{l}\text { Secondary } \\
\text { depth-of-cut }(\mathrm{mm})\end{array}$ & $\mathrm{D}_{\mathrm{s}}$ & 0.40 & 0.60 & 0.80 \\
\hline
\end{tabular}

\section{RESULTS AND DISCUSSION}

To optimize the process parameters (cutting speed, feed rate, primary depth-of-cut and secondary depth-of-cut) using Taguchi approach, a well known $\mathrm{L}_{9}$ orthogonal design matrix for four-factors with three-level has been selected to perform the experiments. The signal to noise $(S / N)$ ratio has been used to analyze the experimental results. The analysis of variance (ANNOVA) technique has been applied to check the feasibility of the experimental results and the percentage contribution of the each factor. Generally, three quality characteristics such as "nominal is better", "higher is better" and "lower is better" are used to analyze the experimental results. In present study, the surface roughness has been taken as response parameter. Therefore, the "lower is better" quality characteristic has been used to analyze the experimental results, which can be determined as $[19,20]$ :

$$
S / N=\frac{1}{n} \sum_{i=1}^{n} y{ }_{i}^{2}
$$

where, $y_{i}=$ observed response or quality value at the $i^{\text {th }}$ experimental run order and $n=$ number of trials at the same level of the parameters. 


\section{ELK}

\section{Asia Pacific Journals}

\section{A. Data Collection}

For the analysis of experimental data, total 9-numbers of experiments are conducted at dual turning setup on center lathe machine. The Taguchi based $\mathrm{L}_{9}$ orthogonal design matrix has been used to conduct the experiments. The experimental observations with the $\mathrm{S} / \mathrm{N}$ ratios for each factor have been summarized in the Table 2.

TABLE 2: Experimental results and $\mathrm{S} / \mathrm{N}$ ratios

\begin{tabular}{ccccccc}
\hline S. No. & $\mathrm{S}$ & $\mathrm{F}$ & $\mathrm{D}_{\mathrm{P}}$ & $\mathrm{D}_{\mathrm{S}}$ & $\mathrm{R}_{\mathrm{a}}$ & $\mathrm{S} / \mathrm{N}$ ratio \\
\hline 1 & 1 & 1 & 1 & 1 & 2.84 & 8.066 \\
2 & 1 & 2 & 2 & 2 & 2.24 & 5.018 \\
3 & 1 & 3 & 3 & 3 & 2.04 & 4.162 \\
4 & 2 & 1 & 2 & 3 & 2.88 & 8.294 \\
5 & 2 & 2 & 3 & 1 & 3.75 & 14.063 \\
6 & 2 & 3 & 1 & 2 & 2.65 & 7.023 \\
7 & 3 & 1 & 1 & 2 & 2.44 & 5.954 \\
8 & 3 & 2 & 3 & 3 & 4.08 & 16.646 \\
9 & 3 & 3 & 2 & 1 & 3.15 & 9.923 \\
\hline
\end{tabular}

\section{B. Analysis of Variance (ANOVA)}

To check the feasibility and adequacy of the experimental results, analysis of variance (ANOVA) technique has been applied. Generally, ANOVA is a statistical technique used to analyze the experimental data. It is used to separate the total variability establish between the random and systematic factors. It is also used to determine the impact of independent variables on the dependent variables during analysis of the regression models $[10,21]$. There are many test used to know the adequacy of data such as sum of square (SS), degree of freedom (DF), mean square error (ME), F-value, percentage (\%) contribution (PC) etc. Therefore, ANOVA analysis has been carried out and summarized in the Table 3.

It has been observed (Table 3 ) that the cutting velocity highly influencing the performance parameter on the average surface roughness during dual turning of the alloy steel within the range of the selected input parameters. The percentage contribution of the each factor for $\mathrm{Ra}$ as cutting velocity $=86.445 \%$, feed rate $=7.075 \%$, secondary depth-ofcut $=3.652 \%$ and primary depth-of-cut $=2.828 \%$.
ELK Asia Pacific Journals - Special Issue

ISBN: 978-81-930411-8-5

TABLE 3: ANOVA results

\begin{tabular}{cccccc}
\hline Factor & SS & DF & ME & F-value & PC \\
\hline $\mathrm{V}$ & 3.948 & 2 & 1.974 & 30.567 & 86.445 \\
$\mathrm{~F}$ & 0.323 & 2 & 0.162 & 2.502 & 7.075 \\
$\mathrm{D}_{\mathrm{p}}$ & $0.129^{*}$ & 2 & 0.065 & --- & 2.828 \\
$\mathrm{D}_{\mathrm{f}}$ & 0.168 & 2 & 0.083 & 1.292 & 3.652 \\
$\begin{array}{c}\text { Pooled } \\
\text { error }\end{array}$ & 0.129 & --- & --- & --- & --- \\
\hline \multicolumn{7}{l}{ Total } & 4.567 & 8 & 2.284 & --- & 100.00 \\
\hline *Pooled factor & & &
\end{tabular}

\section{Optimization using Taguchi Methodology}

Taguchi methodology is a statistical technique used to optimize the single as well as multi-objective optimization problems. It needs to perform the experiments according to the orthogonal design matrix. Therefore, the experimental data summarized in the Table 2 are analyzed to find the $\mathrm{S} / \mathrm{N}$ ratio of the each factor using equation (1). Generally, $\mathrm{S} / \mathrm{N}$ ratios are used to identify the rank and optimal cutting condition for the each controlled parameter. The $\mathrm{S} / \mathrm{N}$ ratios for each factor with their level and respective ranks are summarized in Table 4. It is observed (Table 4) that ranks of each parameter (based on $\mathrm{S} / \mathrm{N}$ ratios) are as cutting speed (I), feed rate (II), secondary depth-of-cut (III) and primary depth-of-cut (IV). Instead of this, the optimal level of parameters i.e. cutting speed, feed rate, primary depth-of-cut and secondary depth-of-cut are as level-3, level-2, level-2 and level-1 respectively. Thus, it is decided that the optimum combination of control parameter as $\mathrm{V}_{3} \mathrm{~F}_{2} \mathrm{D}_{\mathrm{p} 2} \mathrm{D}_{\mathrm{s} 1}$ is more suitable for the better surface quality.

TABLE 4: Effect of factor's level on the S/N ratio

\begin{tabular}{cccccc}
\hline \multirow{2}{*}{ Factor } & \multicolumn{3}{c}{ S/N ratio } & Delta & Rank \\
\cline { 2 - 5 } & Level 1 & Level 2 & Level 3 & (max-min) & \\
\hline V & 5.748 & 9.793 & $10.841^{*}$ & 5.093 & I \\
F & 7.438 & $11.909^{*}$ & 7.036 & 4.873 & II \\
$D_{P}$ & 10.578 & $11.617^{*}$ & 8.059 & 2.519 & IV \\
$D_{S}$ & $10.684^{*}$ & 5.998 & 9.701 & 4.686 & III \\
\hline
\end{tabular}

*Optimal value 


\section{Asia Pacific Journals}

\section{Confirmation Experimentation}

Confirmation experiments have been carried out on the workpiece material as alloy steel i.e. AISI 1040. Firstly, the confirmation experiment has been conducted at the optimal condition of parameters as cutting speed $=30 \mathrm{~m} / \mathrm{min}$, feed rate $=0.40 \mathrm{~mm} / \mathrm{rev}$, primary depth-of-cut $=0.60 \mathrm{~mm}$ and secondary depth-of-cut $=0.20 \mathrm{~mm}$. The Ra value obtained at optimal condition has been compared with Ra value of turned part obtained at initial set condition as speed $=10 \mathrm{~m} / \mathrm{min}$, feed rate $=0.20 \mathrm{~mm} / \mathrm{rev}$, primary depth-of-cut $=0.40 \mathrm{~mm}$ and secondary depth-of-cut $=0.20 \mathrm{~mm}$. The comparative analysis for the $\mathrm{Ra}$ values at different turning condition has been summarized in the Table 5. The graphical presentation of comparative analysis has been shown in the Fig. 3 .

TABLE 5: Comparative analysis for Ra

\begin{tabular}{ccc}
\hline Response & Initial condition & Optimum condition \\
\hline Level & $\mathrm{V}_{1} \mathrm{~F}_{1} \mathrm{D}_{\mathrm{p} 1} \mathrm{D}_{\mathrm{s} 1}$ & $\mathrm{~V}_{3} \mathrm{~F}_{2} \mathrm{D}_{\mathrm{p} 2} \mathrm{D}_{\mathrm{s} 1}$ \\
\hline $\mathrm{S} / \mathrm{N}$ ratio & 8.066 & 1.960 \\
\hline $\mathrm{R}_{\mathrm{a}}(\mu \mathrm{m})$ & 2.84 & $1 . .40$ \\
\hline
\end{tabular}

Percentage improvement in $\mathrm{S} / \mathrm{N}$ ratio $=75.70$

Percentage improvement in $\mathrm{R}_{\mathrm{a}}$ value $=50.70$

It has been observed (Table 5) that the optimal combination of input parameters gives better surface finish as compared to the initial combination of input parameters for the dual turning process. In similar way, the $\mathrm{S} / \mathrm{N}$ ration also improved at the optimal set parameters. The percentage improvements (at optimal condition) in the $\mathrm{S} / \mathrm{N}$ ratio and in the $\mathrm{R}_{\mathrm{a}}$ value are as $50.70 \%$ and $75.70 \%$ respectively.

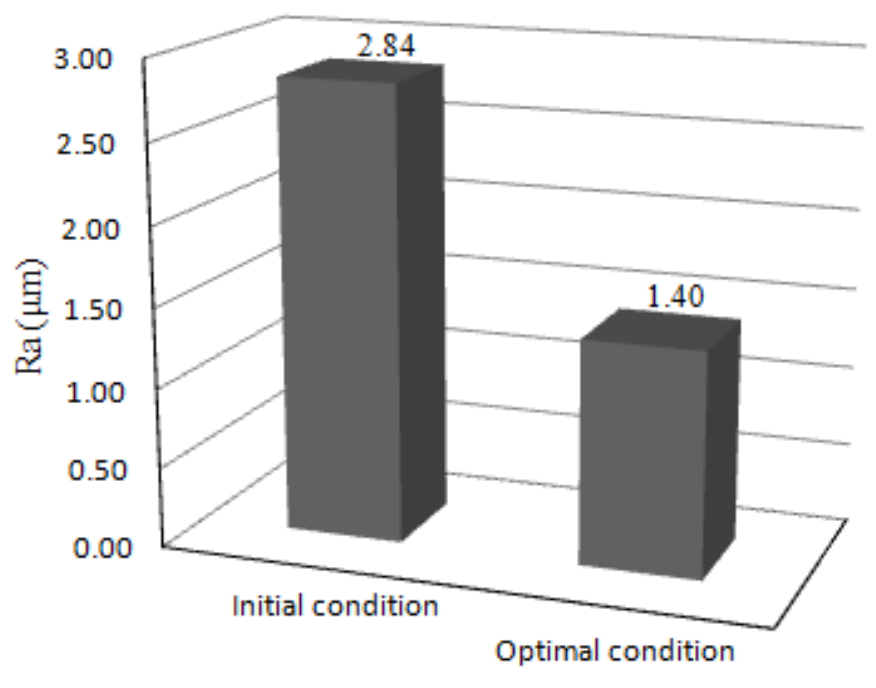

Dualtuming conditions

Fig. 3. Comparison between initial and optimal Ra

\section{CONCLUSIONS}

In present study an effort has made to optimize the process parameter for minimization of the surface roughness during the dual turning of the AISI 1040 alloy steel. The effect of the controlled parameters such as cutting speed, feed rate, primary depth-of-cut and secondary depth-of-cut has been analyzed on the average surface roughness using Taguchi optimization technique. After careful analysis, following conclusions have been drawn:

1. The cutting speed has been found more significant parameter that affects the surface finish during dual turning of the alloy steel.

2. The percentage contributions of the controlled input parameters i.e. cutting speed $=86.445 \%$ and follows by the percentage contribution of the feed rate $=7.075$, secondary depth-of-cut $=3.652$ and primary depth-ofcut $=2.828 \%$ have been obtained from the ANOVA analysis of the experimental data.

3. The primary depth-of-cut has low (among all the process parameters) effect on the surface finish within the range of the selected input parameters.

4. The optimum combination in between the control parameters as $\mathrm{V}_{3} \mathrm{~F}_{2} \mathrm{D}_{\mathrm{p} 2} \mathrm{D}_{\mathrm{s} 1}$ has been obtained with the help of Taguchi approach.

5. The $\mathrm{S} / \mathrm{N}$ has been improved (approximately $75.70 \%$ ) at optimal combination of parameters as compared to the initial condition of controlled parameters.

6. The optimal combination of the input parameters gives better surface finish as compared to the initial combination of the input parameters.

7. The percentage improvement in the surface finish at optimum level of controlled parameters is $50.70 \%$ higher has been obtained as compared to the initial set condition of the dual turning of alloy steel.

\section{References}

[1] A.R. Yildiz, "A comparative study of population-based optimization algorithms for turning operations," Inform. Sci., vol. 210, pp. 81-88, 2012 .

[2] G.K. Lal, Introduction to Machining Science, New Age International Publisher, New Delhi, 1994

[3] M. Saini, R. N. Yadav and S. Kumar, "An overview on turning process," Proceeding of the $1^{\text {st }}$ Int. Conf. Adv. Recent Inn. Mech., Product. Indust. Eng. (ARIMPIE-2015)”, vol. 2, pp. 377-385, 2015.

[4] Y. Sahin and A. R. Motorcu "Surface roughness model for machining mild steel with coated carbide tool", Mater. Design, vol. 26, pp. 321326, 2005.

[5] J. P. Davim, "Design of optimization of for turning parameters for cutting metal matrix composites base on orthogonal arrays", J. Mater Process. Technol., vol. 132, pp. 340-344, 2003.

[6] N.R. Dhar, M. Kamruzzaman and M. Ahamad, "Effect of minimum quantity lubrication (MQL) on tool wear and surface roughness in 


\section{Asia Pacific Journals}

turning AISI-4340 steel", J. Mater. Process. Technol, vol. 172, pp. 299304, 2006.

[7] E. Budak and E. Ozturc "Dynamics and stability of parallel turning operations", CIRP Annals, Manuf. Technol. vol. 60, pp. 383-386, 2011.

[8] R. Kalidasan, V. Ramanuj, D. K. Sharma and S. Senthilvelan, "Influence of cutting speed and offset distance over cutting tool vibration in multi tool cutting vibration", Adv. Mat. Res., vol. 984-985, pp. 100-105, 2014.

[9] C. Brecher, A. Epple, S. Neus and M. Fey, "Optimal process parameters for parallel turning operations on shared surfaces", Int. J. Machine Tool Manuf. vol. 95, pp. 13-19, 2015.

[10] P. J. Ross, Taguchi Techniques for Quality Engineering: Loss Function, Orthogonal Experiments, Parametric tolerance Design, McGraw-Hill, New York, 1996.

[11] M. Kurt, E. Bagci and Y. Kaynac, "Application of the Taguchi methods in the optimization of cutting parameters for surface finish and hole diameter accuracy in dry drilling process", Int. J. Adv. Manuf. Technol., vol. 40, pp. 458-469, 2009.

[12] A. Kakal, M. Gunay and Y. Turgut, "optimization of machining parameters in milling of Ti-Al-4V alloys using Taguchi method", J. New World Sci. Acad. Eng. Sci., vol. 6, pp. 428-440, 2011.

[13] C.Y. Nian, W. H. Yang and Y. S. Tarng, "Optimization of turning operations with multiple performance characteristics", J. Mater. Process. Technol., vol. 95, pp. 90-96, 1999.
ISBN: 978-81-930411-8-5

[14] W.H. Yang and Y. S. Tarng, "Design optimization of cutting parameters for turning operations based on the Taguchi method", J. Mater. Process. Technol., vol. 95, 122-129, 1995.

[15] M. Nalbant, H. Gokkaya and G. Sur, "Application of Taguchi method in the optimization method of cutting parameters for surface roughness in turning”, Mater. Design, vol. 28, pp. 1379-1385, 2007.

[16] E. Yucel, "Modelling and optimization of the cutting conditions in hard turning of high alloy white cast iron (Ni-Hard)", Proceed. IMeche Part C: J. Mech. Eng. Sci., vol 227, pp. 2280-2290, 2012.

[17] I. Asiturk and H. Akkus, "Determine the effect of cutting parameters on surface roughness in hard turning using Taguchi method", Measurement, vol. 44, pp. 1697-1704, 2011.

[18] S. Thamizhmani, S. Saparuddin and S. Hasan, "Analysis of surface roughness by using Taguchi method", Ach, Mater, Manuf. Engg., vol. 20, pp. 503-505, 2007.

[19] G. K. Singh, V. Yadava and R. Kumar, "Multiresponse optimization of electro-discharge diamond face grinding process using robust design of experiments", Mater. Manuf. Process., vol. 25, pp. 851-856, 2010.

[20] B. K. Bhuyan and Vinod Yadava, Experimental modelling and multiresponse optimization of travelling wire electrochemical spark machining of pyrex glass", Proc. IMechE Part B: J. Eng. Manuf., vol. 228, pp. 902-916, 2014.

[21] D.C. Montgomery, Design and Analysis of Experiments. Wiley India, New Delhi, 2013. 